RESENHA

\title{
Exilados e imigrantes: entre a repressão e a resistência
}

\author{
Exiled and immigrants: \\ between repression and resistance \\ Exiliados e inmigrantes: \\ entre la represión y la resistencia
}

RESENHA DE:

VIANNA, Marly de Almeida Gomes; SILVA, Erica Sarmiento da; GONÇALVES, Leandro Pereira (Org.). Presos políticos e perseguidos estrangeiros na Era Vargas. Rio de Janeiro: Mauad X; Faperj, 2014.

Em 10 de dezembro de 2014, a Comissão Nacional da Verdade (CNV) entregou seu extenso relatório à Presidente da República. São cerca de 3.500 páginas relatando as graves violações aos direitos humanos perpetradas durante o período entre 1946 e 1988 . O término do relatório e sua entrega devem ser saudados como um marco na história da democracia brasileira e seu texto serve de referência para o campo de estudos da chamada "justiça de transição".

O relatório, no entanto, se move em campo temporal muito particular: 1946/1988. Essa escolha é plenamente compreensível uma vez os membros da CNV entenderam que seu lugar de atuação deveria ser entre as duas constituições democráticas que balizam o regime autoritário iniciado em 1964. Sabemos, como historiadores, das dificuldades em estabelecer rupturas no fluxo do tempo. Sem dúvida que o fim da ditadura do Estado Novo inaugurou um novo momento político, com outra dinâmica e com novas expectativas. Porém, seria imprudente não perceber continuidades. $O$ viés autoritário de extensos setores da sociedade brasileira nem suas instituições repressivas não 
desapareceu com a nova constituição. A CNV não ignorou no texto do seu relatório essas permanências, mas a história que ela teve de relatar foi outra.

Com isso, a publicação de Presos politicos e perseguidos estrangeiros na Era Vargas, quase simultaneamente à entrega do relatório da Comissão Nacional da Verdade, ganhou especial relevância. Ao tratar do aparato burocrático e policial que foi se estruturando ao longo das décadas de 1930 e 1940 podemos ver um cenário que nos avisa da longa trajetória de violação aos direitos humanos no país e nos diz, também, sobre as diversas formas de resistência construídas nesses anos de repressão.

Com introdução de Francisco Falcon, a coletânea organizada pelos pesquisadores Marly Vianna, Erica Sarmiento e Leandro Pereira Gonçalves, reúne em treze capítulos uma diversidade de estudos sobre as formas da violência de Estado perpetradas durante a chamada Era Vargas. A convivência de várias falas permite que o leitor possa desenhar diferentes percursos em sua leitura, encontrando caminhos e estabelecendo unidades temáticas que lhe são próprias e convenientes. Como é comum às coletâneas, cada leitor terá um livro para ler e cada chave de leitura não se sobreporá a outra.

O livro tem início com um capítulo escrito por Maria Luiza Tucci Carneiro e a escolha parece ter algo de estratégico. A autora escreve um texto intenso e analiticamente agudo sobre a documentação dos Arquivos da Polícia Política brasileira, especialmente a seção cuja documentação se relaciona à seção de São Paulo. A apresentação dessa documentação, tratada por Tucci Carneiro em um projeto conjunto entre a USP e o Arquivo Público do Estado de São Paulo, permite que algumas considerações fundamentais para o livro sejam traçadas: a formação das estruturas policiais, os conflitos entre os agentes estatais e a sociedade civil e o lugar dos intelectuais frente à violência de Estado.

Em um primeiro conjunto de capítulos, que não estão agrupados, mas que oferecem uma unidade temática, encontramos os textos de Alexandre Samis, Marly Vianna, Carlo Romani, Leandro Pereira Gonçalves, Pedro Fagundes e Taís Campelo Lucas. Eles abordam, com várias nuances, as relações dos diversos grupos políticos com o aparato de repressão. Destaca-se nesse momento uma peculiaridade do varguismo, pois sua ação repressiva atingiu tanto anarquistas e comunistas como integralistas e nazistas. Essa repressão ideologicamente "horizontal" ocorre na medida em que as bases do Estado Varguista vão 
se alterando. As novas configurações políticas vão gerando novos inimigos a perseguir.

Em outro registro, mas sem nunca se distanciar, estão os trabalhos escritos por Maria Izilda Matos, Erica Sarmiento, Heitor Loureiro, Rosangela Kimura, Taciana Wiazovski, Fernanda Franchini e Diana Vidal. Eles tratam de temas centrais para o projeto da repressão política, mas indicam um caminho muito particular que é aquele habitado pelo imigrante ou pelo "não-nacional". Portugueses, galegos, russos, judeus, japoneses ou alemães, os imigrantes, mesmo sem uma clara inserção ideológica, foram uma preocupação constante para o aparato repressivo do Estado nacional brasileiro nesse período. As práticas de alteridade do imigrante traziam uma ameaça para unidade cultural da nação e a vasta documentação foi um sintoma da fragilidade da ideia de "nação brasileira". A análise de casos particulares, como a expulsão da cafetina portuguesa Maria Beatriz, citado no capitulo de Maria Izilda Matos é um exemplo do rico quadro da intolerância étnica e das perseguições realizadas contra indivíduos e comunidades tão comuns em tempos de repressão.

Lido assim, os trabalhos reunidos em Presos politicos e perseguidos estrangeiros na Era Vargas revelam dois méritos indiscutíveis. Primeiro, temos a força da pesquisa documental visível em todos os capítulos. O trânsito por vários gêneros de escrita histórica não atrapalha a visão de um grupo de pesquisadores, com muito controle sobre suas fontes. Processos, registros policiais, arquivos públicos e privados são apresentados ao leitor e usados com rigor pelos autores. Em segundo lugar, os diferentes capítulos criam um interessante cenário sobre a produção historiográfica recente no Brasil. Assim sendo, os capítulos tramam diálogos nos quais os recursos da história social, da biografia política e da história das ideias e da cultura são utilizados abrindo interessantes perspectivas de análise.

No entanto, a diversidade e as variações guardam também certos problemas. Os artigos têm ritmos diferentes e cada autor imprime um estilo de escrita que faz a leitura oscilar. Ao mesmo tempo, os artigos parecem corresponder a pesquisas em diferentes momentos da trajetória de seus autores. Há também variações conceituais, por vezes as noções de Estado autoritário ou de violência política, por exemplo, têm abrangências distintas conforme a perspectiva do autor. Essas questões, porém, devem ser vistas como constitutivas da leitura de uma obra coletiva e não devem constituir um empecilho na sua apreciação. 
Retomo, para finalizar, o argumento da relevância do livro Presos políticos e perseguidos estrangeiros na Era Vargas. Seu chamado à memória da tradição autoritária do Estado brasileiro é seu grande mérito e o principal desafio para aqueles que trabalham com os temas e conceitos da difícil temporalidade chamada de "tempo presente".

\section{Maurício Barreto Alvarez Parada}

Departamento de História/PUC-RJ

Recebido: 14 de junho de 2015 Aprovado: 22 de agosto de 2015

\section{Autor/Author:}

MAURÍcIO BARRETO AlvAREZ PARADA <mparada@ig.com.br>

- Professor do Departamento de História da Pontifícia Universidade Católica do Rio de Janeiro, Brasil. Coordena a área de História Moderna e Contemporânea. Especialista em História Social da Cultura, atuando principalmente no âmbito dapolítica, cultura, intelectuais e identidade nacional.

- Professor in the Department of History at the Pontifical Catholic University of Rio de Janeiro, Brazil, where he is head of the area of Modern and Contemporary History. His research is focused on the social history of culture, acting mainly in the fields of politics, culture, intellectuals and national identity. 